\title{
Repertorios comunicacionales en las consultas populares de Arbeláez y Fusagasugá
}

Communicational repertoires in the popular consultations of Arbeláez and Fusagasugá

Repertórios comunicacionais nas consultas populares de Arbeláeze Fusagasugá

\author{
Marisabel GARCÍA ACELAS \\ Corporación Universitaria Minuto de Dios (Colombia) \\ marigarcia@uniminuto.edu \\ Robert Adrian QUINTERO LEGUIZAMON \\ Corporación Universitaria Minuto de Dios (Colombia) \\ robert.quintero@uniminuto.edu
}

Chasqui. Revista Latinoamericana de Comunicación

N. ${ }^{\circ}$ 148, diciembre 2021 - marzo 2022 (Sección Monográfico, pp. 141-16o)

ISSN 1390-1079 / e-ISSN 1390-924X

Ecuador: CIESPAL

Recibido: 30-06-2021 / Aprobado: 12-11-2021 


\title{
Resumen
}

Este artículo caracteriza las prácticas comunicacionales de los comités que promovieron las consultas populares convocadas contra proyectos de extracción minero-energética en dos municipios de Colombia: Arbeláez (Cundinamarca) y Fusagasugá (Cundinamarca). Con este fin, se abordan los factores que originaron el conflicto socioambiental, se reconstruye el proceso de convocatoria a la consulta y se detalla el "repertorio de prácticas comunicacionales" que organizaron los comités promotores, comprendido como la integración de nanomedios y artes populares y su articulación con las acciones de organizaciones sociales que impulsaron las consultas. Se concluye que el proceso de comunicación de los comités robustece el reconocimiento de los conflictos socioambientales en la comunidad, expande y diversifica la opinión pública y contribuye al desarrollo de mecanismos de participación popular.

Palabras clave: conflictos socioambientales, extractivismo, consultas populares, repertorios comunicacionales.

\begin{abstract}
This article characterizes the communication practices of the committees that promoted the popular consultations called against mining and energy extraction projects in two municipalities of Colombia: Arbeláez (Cundinamarca) and Fusagasugá (Cundinamarca). To this end, the factors that originated the socioenvironmental conflict are addressed, the process of calling for consultation is reconstructed and the "repertoire of communication practices" organized by the promoting committees is detailed, including the integration of nanomedia and popular arts and their articulation with the actions of social organizations that promoted the consultations. It is concluded that the communication process of the committees strengthens the recognition of socio-environmental conflicts in the community, expands and diversifies public opinion and contributes to the development of popular participation mechanisms.

Keywords: socio-environmental conflicts, extractivism, popular consultations, communication repertoires.
\end{abstract}

\section{Resumo}

Este artigo caracteriza as práticas de comunicação dos comitês que promoveram consultas populares contra projetos de extração mineralenergética em dois municípios da Colômbia: Arbeláez (Cundinamarca) e Fusagasugá (Cundinamarca). Para tanto, abordam-se os fatores que originaram o conflito socioambiental, reconstrói-se o processo de convocação e detalha-se o "repertório de práticas comunicacionais" organizados pe los comitês promotores, incluindo a integração da nanomídia e das artes populares e seus articulação com as ações das organizações sociais que promoveram as consultas. Conclui-se que o processo de comunicação dos comitês fortalece 
o reconhecimento dos conflitos socioambientais na comunidade, amplia e diversifica a opinião pública e contribui para o desenvolvimento de mecanismos de participação popular.

Palabras-chave: conflitos socioambientais, extrativismo, consultas populares, repertórios de comunicação.

\section{Introducción y discusión a la que se busca aportar}

En la actual fase de valoración del capital, la intensificación de la acumulación por desposesión ha sido adoptada como pauta del modelo de desarrollo y como una de las principales actividades que sirven para atraer inversión extranjera directa en muchos Estados de la región. En el marco de la disputa geopolítica por el control estratégico de recursos energéticos (Ceceña, 2017; Ornelas, 2017), y ante la elevada demanda de abastecimiento de materias primas para el creciente mercado chino, se ha elevado la extracción de minerales y energéticos, lo cual ha provocado de forma concomitante la movilización de organizaciones y movimientos sociales que impugnan la degradación de las condiciones ecosistémicas que garantizan la vida y sustentabilidad de los territorios (Svampa y Slipak, 2015).

En el caso de Colombia es posible afirmar que en las últimas dos décadas se ahondó en el modelo extractivo basado en una política minera y de hidrocarburos que promueve la suscripción de títulos mineros, concesiones territoriales y derechos de explotación de los recursos naturales por diversos métodos (Martínez Ortiz y Aguilar Londoño, 2013). De los 129 conflictos ambientales registrados por el EJAtlas (Global Environmental Justice Atlas) en Colombia hasta 2020 , el $50 \%$ corresponde a actividades extractivas.

Las acciones colectivas y la dinámica contenciosa contra los proyectos minero-energéticos han involucrado la alianza heterogénea de actores sociales, políticos, económicos y, especialmente, ambientales con intereses múltiples. Si bien el repertorio de acciones colectivas ha incorporado los recursos a acciones directas o vías de hecho (movilizaciones, manifestaciones callejeras, etc.), también ha recurrido a vías formales o institucionales incorporadas en el conjunto de mecanismos de participación popular reconocidos por la Constitución política de 1991. Uno de dichos mecanismos destaca por el difundido alcance que ha logrado entre las comunidades que sostienen luchas contra proyectos minero-energéticos. Se trata de la consulta popular (CP), definido como el derecho que tiene la comunidad a participar de forma directa frente a asuntos de transcendencia pública, mediante el procedimiento de sufragio, respecto a una pregunta ligada al hecho trascendental. Resulta importante indicar que el resultado de la convocatoria - es decir, la postura mayoritaria de quienes votan - posee efectos de obligatorio cumplimiento. De acuerdo con los procedimientos que definen la organización de la $\mathrm{CP}$, se reconoce 
la posibilidad de conformar comités promotores que fungen como responsables de las actividades administrativas, financieras y de campaña durante la consulta (Ley 1757, art. 5).

Entre 1991 y 2019 han pasado control jurídico y constitucional once consultas respecto a temas que involucran actividades extractivas, de las cuales se han celebrado diez, ocho de estas desde 2017 (Bocanegra y Carvajal, 2019; Misión de Observación Electoral [MOE], 2012). Un aspecto a destacar de las CP contra proyectos minero-energéticos es la ampliación de la opinión pública frente a temas estratégicos vinculados a los territorios y a la discusión del modelo de desarrollo inherente a ellos (Ramírez y Padrón, 2016).

En tanto mecanismo participativo que involucra acciones híbridas (formales e informales), no solo ha dependido de que los comités promotores de consultas obtengan aprendizajes organizativos (Urkidi y Walter, 2017), sino que, además, ha sido necesario desarrollar prácticas comunicacionales con las que han logrado procesos de difusión, espacios de intercomunicación e incluso apuestas educomunicativas, a partir de lenguajes propios que articulan el recurso a medios alternativos —nanomedios- y artes populares (Downing, 2010). Ello, con el objetivo de promover entre la comunidad el conocimiento sobre las razones que motivan la consulta y, en consecuencia, lograr el respaldo a esta. Se trata de repertorios comunicacionales pensados para distintos ámbitos y públicos basados en múltiples formatos, técnicas y tecnologías, algunas de ellas propias, que promueven la participación. Algunos de estos repertorios tienen una vida efímera, mientras que otros logran sostenerse más allá de la celebración de la consulta. Aun cuando la producción comunicacional responde a la particularidades culturales de las comunidades locales, dichos repertorios en parte recogen experiencias transescalares (Conde, 2017) y, al tiempo, sirven como un modo de llenar el vacío informativo o el escaso cubrimiento de los medios nacionales sobre las consultas.

\section{Marco teórico}

Para aproximarnos a los conflictos desatados por los factores ya nombrados, empleamos la categoría de "conflictos socioambientales", respecto a los cuales la ecología política ${ }^{1}$ ha generado un fecundo acervo investigativo. Entendemos estas formas de pugnacidad como la contraposición de intereses y expectativas opuestas derivadas de un proyecto que impacta a una comunidad. Los conflictos socioambientales implican luchas provocadas por la desigual distribución de recursos y servicios ambientales y por los efectos sociales, económicos y culturales que de ello se desprenden; del mismo modo, también involucran el

1 De acuerdo con Left (2014), "el campo de la ecología política se decanta y arraiga en procesos de terrirorialización en los que se despliegan estrategias, prácticas y procesos político-sociales-culturales en la reapropiación de la naturaleza. [...] es el campo de encuentro, confrontación y convivencia entre diferentes modos de construir la vida humana en el planeta" (p. 225). 
enfrentamiento entre cosmovisiones sobre el ambiente y la vida inherentes a los grupos inmersos en la disputa (Martínez Alier, 2011; Walter, 2009).

Los comités promotores que impulsaron las CP en Arbeláez y Fusagasugá se apoyaron en la constitución y organización de procesos comunicacionales que gozaron de una enorme capacidad de convocatoria. A tales procesos los hemos denominado repertorios de prácticas comunicacionales. Cierto es que distintos trabajos han resaltado la importancia de los proyectos comunicativos para los movimientos sociales. Una línea específica de estudios ha centrado su atención en la designada (a falta de consenso) comunicación popular, alternativa, ciudadana, comunitaria, contrainformativa, etc. Dichas acepciones son un intento de conceptualizar el carácter contrahegemónico y democratizador que adoptan algunas apuestas de comunicación. En nuestro trabajo nos hemos inclinado por utilizar una categoría, pensada desde el enfoque de las teorías de rango intermedio, para recoger el abanico de propuestas comunicativas que surgen de organizaciones y movimientos sociales con el objetivo de promover las consultas populares.

En correspondencia, por prácticas comunicacionales comprendemos la praxis de colectivos o movimientos - de diversa impronta ideológica e intereses políticos, sociales y culturales - orientada a producir, modificar o posibilitar experiencias de sentido en una comunidad. Vistas así, las prácticas comunicacionales son procesos simbólicos y materiales con los que se busca generar interacciones dialógicas que activen escenarios deliberativos en la opinión pública (Habermas, 1986) a partir del uso de un conjunto amplio de medios que repercuta en el nivel de las mediaciones comunicativas. En ocasiones, las tácticas y estrategias de comunicación socialmente heredadas sirven a la praxis comunicacional de los colectivos para configurar repertorios. Este último concepto, según como McAdam, Tarrow y Tilly (2005) lo comprenden, ${ }^{2}$ nos permite identificar el abanico de propuestas y proyectos comunicacionales desarrollados de cara a la promoción de la CP. Tilly (2010) señaló que los repertorios de acción colectiva son los medios que la gente utiliza para alcanzar objetivos comunes. Es decir, los repertorios constituyen horizontes de experiencias colectivas (Svampa, 2009). En tanto es posible advertir el recurso a un conjunto de interacciones de tipo comunicacional practicadas por colectivos, organizaciones y movimientos sociales que convergieron en los comités promotores cuyo propósito común consistió en procurar incidir en el conflicto socioambiental a través de las consultas populares (tanto en Arbeláez

2 McAdam et al.(2005) sostienen que los repertorios representan las formas culturalmente modificadas que tiene la gente de interactuar en la contienda política. Según estos autores, el concepto de repertorio "es una metáfora teatral -repertorio- para transmitir la idea de que los participantes en las reivindicaciones públicas adoptan unos guiones que ya han sido escenificados anteriormente, o por los menos los han observado. No inventan simplemente una nueva forma de acción eficaz ni expresan cualquiera de los impulsos que sienten, sino que reelaboran las rutinas ya conocidas en respuesta a las circunstancias del momento" (p. 96). 
como en Fusagasugá), consideramos adecuado referir que en los casos señalados se configuraron repertorios de prácticas comunicacionales.

El estado de arte que acompañó esta investigación detectó el interés que ha suscitado la CP como mecanismo de participación directa frente a proyectos energético-mineros en la región. La mayoría de estos trabajos se concentran en analizar la CP en tanto instrumento y proceso político empleado por las comunidades involucradas en conflictos socioambientales (Conde, 2017; Conde y Le Billon, 2017; Helwege, 2015; Hincapié, 2017; Urkidi, 2011; Urkidi y Walter, 2011, 2017). No obstante, son escasos los trabajos que han procurado analizar la comunicación como un aspecto estratégico de la práctica política y educativa que involucran las consultas. ${ }^{3}$ A partir del trabajo de campo realizado en los dos municipios, se logró establecer el carácter central que ocupa el repertorio de prácticas comunicacionales cuando estas se integran a la acción de las organizaciones promotoras de las CP.

\section{Metodología}

Este trabajo se realizó atendiendo las premisas metodológicas de la investigaciónacción participativa. En tal sentido, se privilegió el rompimiento sujeto-objeto, propio de la lógica dominante del canon investigativo, y se priorizó una relación sujeto-sujeto en la que la participación o autorreflexión de las organizaciones sociales resultó esencial para el desarrollo del proceso de indagación. La relación dialógica entre el equipo investigador y las organizaciones promotoras de las consultas populares configuró un proceso de participación reflexiva sobre nuestro asunto de indagación: los repertorios de prácticas comunicacionales.

Desde esta perspectiva, se consideró fundamental que fuesen directamente los creadores, operadores o productores de las prácticas comunicativas quienes a partir de su experiencia procurasen esclarecer desde la perspectiva conceptual los alcances, límites, propósitos y métodos contenidos en sus apuestas. Para efectuar tal procedimiento, realizamos entrevistas semiestructuradas y abiertas con miembros de los comités promotores, en donde se reconstruyeron las características y los sentidos de dichas prácticas a través del relato histórico y de los recorridos territoriales por los municipios.

El proceso de investigación implicó la inmersión en los respectivos municipios con la cual buscamos conocer los procesos de difusión de las consultas. En el caso de Fusagasugá, participamos en la jornada donde se llevó a cabo la CP. En cuanto al trabajo de campo, a través de observación participante recolectamos información sobre las organizaciones promotoras de las consultas, profundizamos junto a ellas en los factores detonantes del

3 Existe una abundante bibliografía que problematiza a escala teórica y con estudios de caso la relación entre medios de comunicación y movimientos sociales. En este trabajo se tuvieron en cuenta especialmente los aportes de Capriles (2016), Castells (1999), Downing (2009; 2010), Carabaza González (2006), Rodríguez (2010) y Zibechi (2007). 
conflicto socioambiental y, además, acopiamos muestras de las prácticas comunicacionales en formato impreso y digital (volantes, carteles, boletines informativos, revistas, fotografías de murales, programas radiales y videos promocionales). Asimismo, sostuvimos entrevistas con miembros de la administración municipal y miembros de corporaciones públicas (concejales y alcaldes), dado que dichas consultas fueron convocadas por autoridades políticas del municipio. El conjunto de información recabada y construida fue sistematizada utilizando algunas categorías que conforman la perspectiva de la interacción estratégica de los movimientos sociales (Oseguera, 2017). Dicho ejercicio se elaboró de forma particular para cada una de las consultas estudiadas.

\section{Resultados}

\subsection{Comunicar la consulta: los comités promotores en la CP de Arbeláez}

\subsubsection{Arbeláez vota no}

Quienes hacían parte del censo electoral de Arbeláez (localidad de la región central de Colombia) tuvieron opción de definir, el domingo 9 de julio de 2017, si se podían realizar actividades asociadas a la extracción minero-energética a gran escala en el municipio. De un potencial de 8872 votantes, 4376 ejercieron su derecho de forma válida; de estos, 4312 se inclinaron por el no, y 38, por el sí. La consulta obtuvo validez dado que sobrepasó el requisito del umbral, cifrado en 2956 votos (“Arbeláez, segundo municipio", 2017). La pregunta que motivó la consulta fue: “¿Está usted de acuerdo, Sí o NO, con que, en el municipio de Arbeláez Cundinamarca, se realicen actividades de sísmica, exploración, explotación y lavado de materiales de hidrocarburos y/o minería a gran escala?".

El factor que detonó el conflicto socioambiental en Arbeláez fue la decisión que adoptó en 2009 la ANH respecto a la definición de las áreas geográficas que harían parte de la denominada Ronda Colombia 2010. Este es el nombre que se le dio a la política minero-energética que promovió la celebración de contratos de asociación entre particulares y el Estado para la exploración y explotación de crudo mediante la figura de "bloques". En efecto, allí se determinó que parte del territorio del Sumapaz podría ser objeto de actividades asociadas al negocio de los hidrocarburos.

Una vez suscritos los contratos de explotación, la desinformación sobre las actividades realizadas por las empresas en los territorios generó desconfianza entre la comunidad. ${ }^{4} \mathrm{Al}$ parecer, algunas de estas actividades comenzaron en el campo en 2012 sin socialización previa por parte de las compañías. La lógica desinformativa de las petroleras, en el contexto de una dinámica organizativa de

4 "La carta que juega la petrolera es la de no comunicar, o comunicar a medias", sostuvo Luis Jaime Ortiz, miembro del Colectivo Guacaná. 
múltiples colectivos medioambientales y agremiaciones campesinas surgidos años atrás en el Sumapaz, contribuyó a detonar el conflicto socioambiental alrededor de la disputa por las implicaciones o afectaciones de los proyectos minero-energéticos habilitados.

Un evento crucial en el desarrollo del conflicto fue un foro realizado en 2015 en el vecino municipio de San Bernardo, donde las petroleras presentaron un informe sobre el impacto ambiental de los proyectos de explotación de hidrocarburos. A juicio de uno de los comités promotores de la CP en Arbeláez, la generalidad y los vacíos del informe incrementaron la inconformidad de la comunidad frente a la posibilidad de iniciar por primera vez actividades de exploración petrolera en la región. En paralelo, la interacción con organizaciones medioambientales del Sumapaz, en especial la organización Agua Sí, Petróleo No, sentó las bases para promover procesos organizativos a partir del aprendizaje social observado en otras experiencias de lucha en torno a conflictos socioambientales.

De allí surgió la iniciativa de crear una veeduría ciudadana, que más tarde se llamó Veeduría Ecológica de Arbeláez (VEA), con el objetivo de hacer seguimiento del proyecto petrolífero y de organizar acciones ciudadanas de vigilancia de este. De las alianzas, encuentros e intercambios comunicativos con ONG, colectivos ambientales y expertos en el campo de la ecología y geología, con quienes se logró profundizar en el reconocimiento de la problemática, surgiría la propuesta de llevar a cabo una CP.

\subsubsection{Repertorios de acción colectiva}

Las acciones colectivas adelantadas en Arbeláez en torno al conflicto socioambiental, al igual que las organizaciones que las impulsaron, fueron múltiples y heterogéneas. No solo aprovecharon la estructura de oportunidades políticas emanada de la facultad de convocar por iniciativa ciudadana consultas populares, sino que acudieron a un abanico de iniciativas mediante las cuales posicionaron sus demandas e intereses en la esfera pública (Radio Zumba La Turba, 2017). Según Luis Jaime Ortiz, no se trató tan solo de una apuesta en contra de las petroleras, en tanto que las consultas populares son un proceso de construcción de ciudadanía; o sea, el hecho de que se puedan hacer en un pueblo es una manera de desarrollo de la Constitución ejercer un derecho, entonces los derechos no son contra nadie (Radio Zumba La Turba, 2017).

Como afirmamos anteriormente, el sujeto colectivo de las consultas fue heterogéneo. Los comités promotores de la consulta fueron el actor más visible, si bien no el único, y respondieron a distintos proyectos e intereses sociopolíticos. En Arbeláez no se inscribió ningún comité por el sí, mientras que se inscribieron los siguientes seis comités por el no (Castañeda, 2017): Comité por el NO, Comité por el NO Salvemos el Agua, Comité Familiar por el NO, 
Comité de Agricultores por el NO, Representante, Comité por el NO, y Comité Arbeláez Vota NO.

Si bien el trabajo de difusión se dividió entre distintos comités, la idea fue sostener una unidad de criterio en la campaña bajo el lema "Arbeláez vota no". De hecho, la división en múltiples organizaciones respondió a la idea de evitar que con un único comité se provocaran discusiones que inmovilizaran la promoción de la CP. Por otra parte, la presencia de partidos políticos no fue del todo visible aun cuando estos tuvieron incidencia en el desarrollo de la consulta. Una muestra de ello fue el apoyo del Polo Democrático y el Partido Verde, quienes respaldaron la consulta mediante convocatoria pública e interpusieron recursos administrativos cuando hizo falta solicitar información ante los organismos técnicos del Estado. Asimismo, otras fuerzas políticas (Partido Conservador, Partido Liberal y Cambio Radical) brindaron un respaldo tenue a la CP más bien a razón del cálculo político. El apoyo de expertos en ecología de la Universidad Javeriana, a través de la Cátedra Augusto Ángel, devino fundamental a tal propósito. Se trató, pues, de cambiar el escenario de públicos desinformados y de acceso asimétrico a la información, conveniente a los fines de las petroleras.

De igual manera, la experiencia transmitida por activistas partícipes de consultas populares como la de Piedras (Tolima) en 2013, Cabrera (Cundinamarca) en febrero de 2017 y Cajamarca (Tolima) en marzo de 2017 brindaron pautas sobre qué y cómo era necesario organizar y movilizar para obtener el respaldo de la población (en cada una de las entrevistas, los integrantes de los comités enfatizaron el rol clave de las redes ambientalistas para potenciar la organización de la consulta).

\subsubsection{Repertorios de prácticas comunicacionales}

Algunas de las prácticas se encaminaron a servir como mecanismos de difusión del mensaje asociado a la convocatoria de la consulta, para lo cual se adoptaron formas tradicionales de comunicación. El empleo de aquellas formas heredadas se produjo en el marco de una elección estratégica de los medios, formatos y estilos de comunicación que se adaptaban con mayor eficacia al ethos cultural de los habitantes del municipio. De igual modo, se concibieron procesos de comunicación que propiciaron la interacción y el encuentro de la comunidad en torno a la participación social necesaria para la búsqueda de opciones a la iniciativa impulsada por el Gobierno central y por los agentes corporativos.

Tales procesos interpelaron a la comunidad sobre las afectaciones socioambientales asociadas a la explotación de hidrocarburos, al tiempo que se apoyaron en diseños edocumunicativos, creaciones artísticas y prácticas carnavalescas típicas del municipio para fortalecer el llamado a la participación social. Estas últimas produjeron una recomposición de los sentidos heredados y potenciaron la resignificación del conflicto desde una perspectiva ecológica por parte delos habitantes del pueblo. Alabrir el repertorio de acción comunicacional 
a la iniciativa de distintos grupos sociales, integrar el lenguaje coloquial, las creencias y los valores dominantes de la comunidad y refuncionalizar el sentido común — que sustenta la interpretación de la cotidianidad social-, los comités promotores lograron amplificar la acción contenciosa y fortalecer la convocatoria a la CP. Con base en el eslogan "Arbeláez vota no", el repertorio involucró acciones comunicacionales ejecutadas directamente por los comités a través de medios y estrategias propios para los que no se requirió o descartó la mediación tecnológica (a estas, por ende, las hemos denominado acciones directas). ${ }^{5}$

Las acciones directas se basaron en visitas puerta a puerta y en la elaboración de murales, volantes, carteles, pasacalles y estampados (algunos de ellos hechos a mano). Los símbolos y mensajes irradiados a través de estas formas hicieron énfasis en el agua y el ecosistema del páramo en tanto bienes naturales comunes a proteger mediante la consulta (recuérdese que el municipio hace parte de la provincia del Sumapaz, donde justamente se encuentra uno de los más extensos ecosistemas de páramos de Colombia). De igual modo, a partir de aquellas acciones comunicacionales, se exhortó a la comunidad a participar en los distintos foros, conversatorios e incluso un cabildo municipal que tuvieron por tema el impacto del sector de hidrocarburos en los territorios.

Otras acciones directas implicaron un mayor nivel de elaboración y organización. Tal es el caso de la estrategia educomunicativa, basada en un enfoque de pedagogía popular, en torno a la cual se elaboraron talleres, conversatorios y encuentros masivos en espacios cubiertos, en los que se emplearon el diseño de maquetas y dioramas para explicar de forma didáctica las implicaciones del extractivismo. El público al que se dirigieron las actividades fue diverso, con el fin de situar la problemática en el conjunto de la comunidad y no solo en los posibles votantes de la consulta. De igual modo, resulta importante mencionar el uso de expresiones artísticas como la puesta en escena de una obra de teatro callejero o de relatos orales compartidos en público (cuentería), presentados en un espacio emblemático para la comunidad, como es la plaza de mercado.

Por último, respecto al repertorio de acciones comunicacionales directas, resulta clave referir la celebración extemporánea de una festividad conocida como la "diablada" o la "pelotera", que, al contar con más de un siglo de tradición, despierta un enorme interés entre los habitantes de la región. La fiesta se suele realizar en la plaza central en el mes de diciembre, y recrea la idea mítica de que con el diablo no se debe jugar (personas disfrazadas de diablo golpean con fuetes hechos de vejiga de vaca o marrano a quienes osen molestar a los diablos). La organización de dicha fiesta exige un arduo trabajo colectivo en el que participan personas de todas las edades, clases sociales y géneros. En mayo de 2017, justo algunas semanas antes de la CP, los comités promotores lograron que

5 Es posible hallar una muestra fotográfica detallada de muchas de estas acciones en la cuenta de Facebook del Colectivo Guacaná (s.f.). 
se realizara una versión especial de "la pelotera", en la que quienes hicieron las veces de diablos portaron camisas alusivas a las corporaciones petroleras que simbolizaban el mal.

No menos importante fue el conjunto de medios y experiencias que apoyaron el repertorio de acciones comunicacionales indirectas, tales como programas y cuñas radiales, perifoneo barrial y mensajes de personajes de la farándula nacidos en el municipio en apoyo a la consulta que fueron difundidos a través de redes sociales y YouTube, pódcast, memes, etc. El abanico de acciones enmarcadas en este terreno se dirigió a resolver la escasa atención prestada por los medios de comunicación locales y nacionales al asunto en conflicto (publificación) y a narrar, a contracorriente de las versiones dominantes, el porqué y el para qué de la CP.

Luis Ortiz y Javier Linares sostuvieron que se determinó enfocar la estrategia comunicacional en los habitantes de los municipios donde se convocaron las consultas populares, puesto que eran ellos en quienes residía la posibilidad de decidir, pero, así mismo, consideraron que de habérsele concedido más atención a medios nacionales se hubiese podido perder el sentido del mensaje que querían promover los comités promotores (L. Ortiz y J. Linares, entrevista personal N. 1, 16 de mayo de 2019). En el mismo sentido, Maximiliano Castellanos nos dejó saber la importancia de mantener una unidad en el mensaje de la publicidad; en este caso, como los comités de impulso a la consulta abogaban por votar no a la explotación petrolera, se insistió en dicha idea: "Una estrategia fue volvernos el municipio más pesimista durante tres meses... no, no, no. Para no confundir a la gente con el sí, como había publicidad de sí al agua, una estrategia era no confundir, entonces nos teníamos que convertir en el municipio más negativo del mundo: promovimos el no, no, no, para cuando llegara la gente a votar, no se confundieran" (M. Castellanos, entrevista personal N. 2, 16 de mayo de 2019).

Un ejemplo emblemático del repertorio de acciones comunicacionales indirectas fue el diseño de lo que podríamos denominar, con Downing (2010), nanomedios, es decir, medios a pequeña escala acondicionados por los movimientos sociales para potenciar la construcción e irradiación de nuevos sentidos que se construyen desde la cotidianidad de las luchas y la contienda política. El programa Radio pirarucú, ${ }^{6}$ un pódcast de máximo siete minutos elaborado por Luis Jaime Ortiz y distribuido en la plataforma de audio en línea SoundCloud (y sitios Web 2.0).

6 En la cortina que introduce el programa se puede oír: "Radio pirarucú: comunicación urgente para hablar de medio ambiente". El pirarucú es un pez amazónico del precámbrico en peligro de extinción; el nombre del pódcast es una alegoría a la amenaza que pesa sobre los ecosistemas y la persistencia de la vida. 


\subsection{Fusagasugá, la consulta popular más grande del país en torno a proyectos extractivos}

\subsubsection{Queremos agua, queremos paz, multinacionales fuera del Sumapaz}

La CP llevada a cabo el 21 de octubre de 2018 en Fusagasugá (Cundinamarca) fue primera contra el fracking. Las nueve consultas desarrolladas los años anteriores se llevaron a cabo en municipios que contaban con menos de 10000 habitantes, y en todos los casos la votación fue en contra de los proyectos extractivos. ${ }^{7}$ En el municipio de Fusagasugá se encontraban habilitadas para votar 104538 personas, y hubo un total de 39499 votos, lo cual superó el umbral de 34846 personas (Registraduría Nacional del Estado Civil, 2018). Como resultado, el 99,49\% del total de votantes respondió no a la pregunta “¿está usted de acuerdo, sí o no, que en el municipio de Fusagasugá se realicen actividades de exploración, perforación y producción de hidrocarburos, fracking y minería a gran escala?", mientras que 202 personas votaron sí.

Si bien hubo intentos de socializar los proyectos de exploración y extracción petrolera Cor 4 y 33 con la comunidad durante 2015 y 2016, estos se encontraron con una fuerte resistencia social. En estas reuniones se hizo evidente el descontento colectivo debido a que los argumentos de las empresas desdibujaban los impactos del proceso de explotación, cuando las comunidades se habían informado previamente sobre los impactos ambientales con universidades y centros de investigación. Al respecto, las comunidades establecieron un eslogan que repetían en cada espacio convocado por las empresas: "Como no vamos a dejar hacer explotación, no necesitamos socialización” (Patricia Rodríguez, entrevista personal N. 3, 4 de diciembre de 2018).

Tal como lo afirman Botia Flechas y Preciado Beltrán (2019), en Fusagasugá fueron principalmente las organizaciones de usuarios de los acueductos comunitarios quienes iniciaron los procesos de protesta y movilización para la reivindicación del territorio, denunciando la posible modificación de la vocación agrícola y las afectaciones sobre el suelo y el agua: "De acuerdo con la Contraloría de Cundinamarca (2016), actualmente existen en la cuenca del río Sumapaz 143 acueductos rurales, que brindan el agua a 37757 usuarios y benefician una población aproximada de 151028 personas" (p. 14).

7 El contexto de esta votación está determinado por la decisión de la Corte Constitucional, que amparó los derechos fundamentales de la empresa Mansarovar Energy Colombia al debido proceso y al acceso a la justicia para el caso de la consulta popular realizada en Cumaral (Meta). En el anuncio de la sentencia se afirma que el mecanismo de las consultas populares no tiene efectos para frenar o vetar los proyectos extractivos, precisando que los recursos del subsuelo pertenecen a la nación y no a los municipios. Tal decisión no generó un pronunciamiento particular sobre el caso de la consulta en Fusagasugá, pero sí produjo incertidumbre sobre el futuro del mecanismo de participación. 


\subsubsection{Repertorios de acción colectiva}

La acción colectiva no solo debe comprenderse en el marco del desarrollo de la consulta, sino que debe ser vista como la articulación de todas las acciones llevadas a cabo con anterioridad a esta que permitieron consolidar una estructura organizativa para su desarrollo. En consecuencia, la acción contenciosa tomó forma a través de acciones jurídicas, movilizaciones y protestas permanentes. Como antecedentes recientes, se puede ubicar una amplia gama de actividades en defensa del páramo del Sumapaz, dentro de las cuales cabe resaltar algunos hitos.

En mayo de 2013, varias organizaciones sociales del municipio iniciaron discusiones regionales con relación al agua como recurso hídrico de gran importancia y cuidado, las cuales eran principalmente lideradas por un estudiante de la Universidad de Cundinamarca que tenía como tesis de grado ese tema, y dictó diversos talleres mostrando lo sucedido en la Guerra del Agua en Bolivia y la organización de la gente para defender el recurso (Patricia Rodríguez, entrevista personal N. 3, 4, de diciembre de 2018).

Un año después, durante 2014, se desarrolla el Paro Nacional Agrario, y las organizaciones sociales con trayectoria en Fusagasugá decidieron convocar una marcha-carnaval en defensa del agua y el territorio hacia la Plaza de Bolívar de Bogotá en el mes de septiembre. En el marco de este escenario, se radicó un derecho de petición respaldado por más de 25000 firmas (Patricia Rodríguez, entrevista personal N. 3, 4 de diciembre de 2018).

A este repertorio de acción colectiva se sumó el uso de acciones de tutela, las cuales fueron instauradas por el derecho a un ambiente sano y el derecho humano al agua. Según Botia Flechas y Preciado Beltrán (2019), solo hasta marzo de 2017 se habían radicado en relación con este tema 2376 tutelas, "190 en Icononzo (Tolima), 4,2 en San Bernardo, 621 en Pandi, 1200 en Arbeláez y 323 en Fusagasugá" (p. 15). Al respecto, Mónica Silva afirma que, dada la dimensión de la lucha, fue necesario buscar aliados con amplios conocimientos en derecho y con experiencia en conflictos ambientales que posibilitaran avanzar en este plano. Otro elemento que ayudó a consolidar la acción contenciosa fue el de las distintas luchas por la producción agroecológica, la defensa del territorio y la reivindicación del campesinado como sujeto de derechos, las cuales han sido parte del proceso histórico de lucha en el Sumapaz y fueron claves en la formación de una colectividad concientizada frente a los impactos ambientales de los proyectos extractivos (entrevista personal N. 4, 3 de diciembre de 2018).

El sujeto colectivo protagonista de la CP es bastante diverso. Por una parte, quienes impulsaron la acción colectiva de forma más terminante fueron los comités promotores, dentro de los cuales se encuentran Fusunga, Comité Todos por Fusagasugá, No a la Minería Fuerza Verde Ciudadana, OSAS, Comité Veredas del Sur y Emserfusa. Sumados a ellos están los partidos políticos que apoyaron la CP, dentro de los cuales están el Polo Democrático, el Partido Verde, 
el Partido Liberal, el Centro Democrático, las FARC, el MIRA y la UP. De forma tal que, como afirma Patricia Rodríguez, "teníamos a uno del partido FARC y uno del Centro Democrático, juntos, repartiendo volantes" (entrevista personal N. 3, 4 de diciembre de 2018). Por otro lado, los docentes y estudiantes de las instituciones educativas de nivel primario, secundario y superior del municipio jugaron un papel fundamental, y un último actor protagónico fue, sin lugar a duda, la Alcaldía y el Consejo Municipal, instancia desde la que se convocó el proceso de CP ante las correspondientes instancias del Gobierno nacional. Como opositores a la acción colectiva se han identificado las empresas Alange Energy y Canacol Energy y una facción del partido Centro Democrático, la cual hizo campaña abierta por el sí.

Dentro de las oportunidades políticas se reconoce la existencia de la Mesa Minero-Energética como alianza nacional de organizaciones ambientales antagónicas a la expansión del modelo extractivista, la cual permitió articular comités promotores de consultas anteriores como los de Cajamarca, Arbeláez y Cumaral. En esta misma categoría se encuentra la alianza a escala regional en la provincia del Sumapaz con la coordinadora de Aguas del Norte y otros sindicatos que hicieron aportes solidarios para el proceso social (Mónica Silva, entrevista personal N. 4, 3 de diciembre de 2018). Otra oportunidad identificada por las organizaciones se encuentra en el papel del ejercicio periodístico realizado en Semana Sostenible ("El peligro de querer extraer petróleo", 2017), que se puede describir "como uno de los pocos medios masivos de comunicación que dio voz a las comunidades y presentó la problemática de forma profunda” (Patricia Rodríguez, entrevista personal N. 3, 4, de diciembre de 2018).

Como amenazas políticas se registran: el papel jugado por las altas cortes, principalmente con el fallo de la Corte Constitucional que antecedió la consulta; el discurso desarrollista usado por las empresas petroleras en los intentos de socialización, "que incluso [llevó] a tildar a los líderes y lideresas de las consultas de ir en contra del progreso local" (Patricia Rodríguez, entrevista personal N. 3, 4 de diciembre de 2018), y la acción de grupos paramilitares que profirieron amenazas a algunos miembros de los comités promotores cuatro días después de que fuera fijada la fecha de la consulta.

\subsubsection{Repertorios de las prácticas comunicacionales}

A finales de septiembre de 2018 se fijó como fecha de la consulta el día 21 de octubre, lo que implicó un mes de proceso pedagógico y convocatoria. El objetivo de quienes lideraban los comités promotores fue convocar a la mayor parte de los habitantes del municipio a votar en contra del extractivismo, a través de un ejercicio educomunicativo y consiente que tuviera como eje la identidad por el territorio y la autonomía de las comunidades (Mónica Silva, entrevista personal N. 4, 3 de diciembre de 2018). 
Enelcortotiempolograronponerencirculaciónrepertorioscomunicacionales compuestos por diversas prácticas comunicacionales - algunas directas y otras indirectas - contundentes al momento de ampliar el proceso de concienciación entre los habitantes del municipio. Entre las prácticas indirectas se destacan las cuñas radiales, las entrevistas y los debates transmitidos en las emisoras Nueva Época y Toca Stéreo, los cuales, al ser difundidos por el medio de comunicación más usado por los campesinos, tuvieron un impacto focalizado en la población rural. Se logró vincular paulatinamente otros medios de comunicación que inicialmente no permitían ampliar la difusión del mensaje. Tal fue el caso de emisoras y periódicos locales, según afirma Rodríguez.

También se diseñaron afiches, se compusieron canciones y se pintaron murales en las vías aledañas, ubicados estratégicamente en los lugares más visitados del municipio, tales como colegios y puentes, donde se plasmaban paisajes junto a eslóganes como “¡Agua sí, petróleo no!”, ‘Agua y agricultura sí, petróleo y minería no!”, “¿La universidad es el páramo del conocimiento y cada estudiante es un frailejón que debemos preservar!” “ “iNO al saqueo de nuestros recursos naturales! ¡Que la historia no se repita!”.

Este tipo de prácticas fueron fundamentales dado la cantidad de habitantes del municipio y su extensión en términos territoriales. Como ya se ha mencionado, al ser la CP con el umbral más alto en el país, debido al número de personas habilitadas para votar, el repertorio comunicacional se concentró en prácticas comunicaciones indirectas, y la masificación de su mensaje a través de lo digital, particularmente, las redes sociales: allí se difundieron, inicialmente, mensajes muy generales con relación al conflicto ambiental, el extractivismo y los intereses de las empresas; y posteriormente, fueron más concretos, tales como: puntos de votación, horas que estarían abiertas las urnas, hora a la que se espera tener resultados, umbral a superar, entre otros. (Mónica Silva, entrevista personal N. 4, 3 de diciembre de 2018).

Así como las formas clásicas de la comunicación fueron apropiadas y puestas en función de decirle no el proyecto minero energético, otras se caracterizaron por recomponer los sentidos heredados, dentro de ellas cabe mencionar una serie de videos realizados por un youtuber del municipio que explicaba de forma pedagógica qué era el fracking, así como la publicación de imágenes, eslóganes, videos de personas famosas que apoyaban la consulta y los resultados de otras consultas desarrolladas anteriormente.

Con relación a las prácticas comunicacionales directas con impacto en la convocatoria de la consulta, se pueden ubicar interesantes ejercicios educomunicacionales como las visitas puerta a puerta por los barrios del municipio, estrategia que permitía ampliar cara a cara, la explicación de los impactos del proyecto, la relevancia de desarrollar la CP y la necesidad de que las comunidades se pronunciaran frente a esta decisión. La dinámica urbana de Fusagasugá, permitió realizar semáforos humanos en las horas pico de tráfico, jornadas de estampados en colegios y universidades, la impresión y divulgación 
de bonos a los comerciantes con imágenes de paisajes, y el perifoneo por los barrios más poblados.

$\mathrm{Al}$ respecto, Patricia Rodríguez afirma que fue "una estrategia comunicativa directa muy importante, en tanto que se va saludando a la gente y se le va llevando el mensaje; se usó para decirle a la gente que la consulta seguía vigente y que era necesario que votara" (Patricia Rodríguez, entrevista personal N. 3, 4. de diciembre de 2018). Algunas de las prácticas directas que permitieron la recomposición de los sentidos heredados fueron, por un lado, la distribución de manillas azules, que identificaban a las personas como guardianes del agua y se entregaban personalmente ampliando los referentes ambientales de los que parten los comités promotores, $y$, por otro, las marchas-carnavales y los eventos culturales llevados a cabo en las plazas públicas, que recogían herramientas propias del arte popular local para vincular a los habitantes con la acción colectiva.

El componente educomunicativo de los repertorios utilizados alentó a que los colegios llevaran a cabo consultas simbólicas y concursos de dibujo relacionados con el valor del agua, haciendo participes a niños, niñas y jóvenes quienes se convirtieron en eslabones fundamentales en el interior de los hogares e invitaron al resto de la familia a sumarse a la acción colectiva. Los marcos interpretativos significativos para acudir a la idiosincrasia de la población y desde allí generar una identidad cultural en los habitantes retrotrayeron elementos propios del ethos del municipio anclados a la defensa del páramo del sumapaz, la campesinidad, los impactos ambientales y la diversidad productiva, se ubican "símbolos del páramo, su vegetación, el agua y la diversidad productiva; otro símbolo fue el poncho, así como los chigüiros del caso de Casanare, que mostraban las consecuencias ambientales de otros procesos extractivos" (Patricia Rodríguez, entrevista personal N. 3, 4, de diciembre de 2018).

\section{Conclusiones}

Los proyectos extractivos asociados a commodities, han generado conflictos socioambientales con nefastos efectos sobre las comunidades en el país. Las CP analizadas en el presente artículo son parte del amplio repertorio de acciones colectivas al que han recurrido las poblaciones afectadas y mediante las cuales han planteado respuestas que propugnan por la autonomía, la autodeterminación y un profundo cuestionamiento al modelo de desarrollo. Dichas consultas se caracterizaron por convocar actores sociales heterogéneos que, con la intención de participar en asuntos públicos, detonaron potentes ejercicios comunicativos de carácter contrahegemónico. Las iniciativas conocidas, si bien generalmente no contaron con grandes producciones, fueron profundamente originales en su contenido y su forma, al combinar procesos de información, denuncia, problematización y concientización sobre la extracción y sus repercusiones. 
En lo que respecta a la caracterización de los repertorios de las prácticas comunicacionales, se exponen los siguientes aspectos identificados:

La comunicación utilizada no solo impulsó nuevas expresiones del movimiento social ambiental a escala municipal y nacional, sino que se constituyó como soporte indispensable para las organizaciones sociales ya consolidadas. En consecuencia, esta se puede identificar como una herramienta de trabajo popular que permitió que la acción colectiva se irradiara a partir de los significados compartidos, las experiencias comunes y los sentidos coincidentes, todos ellos evocados con una comprensión del ethos cultural local.

De tal forma, los comités promotores motivaron la inserción de nuevos miembros provenientes de la base social a través de la práctica, y derribaron el prejuicio de que el conocimiento en el campo comunicativo y sus respectivos productos son del manejo único de especialistas. Así, prosperaron piezas comunicativas sui generis con un alcance significativo, que propugnaron por visibilizar las prácticas cotidianas de los pobladores y expresar el cuidado y defensa de las mayorías sobre los bienes comunes. En dicho ejercicio fue fundamental la amplia relación con lo digital y las redes sociales, la cual permitió tanto la masificación del mensaje como la adhesión de otros sectores de la sociedad que no necesariamente se veían directamente afectados por el conflicto, pero sí interpelados por la reivindicación divulgada.

Las disputas colectivas contra la lógica extractiva facilitaron la emergencia de reivindicaciones centradas en la justicia ambiental. Esto hizo posible que las acciones colectivas y sus marcos de sentido fueran permeados por referentes ecologistas y ambientales. Queda por esclarecer si quizá un incremento en el interés por las problemáticas ambientales en la opinión pública sirvió como una estructura de oportunidad para movilizar a los habitantes de los municipios. Lo cierto es que el repertorio de acciones comunicacionales se fundamentó en un proceso educomunicativo en el que la agenda ambiental jugó un papel indiscutible. El uso de artes populares (obras de teatro, cuentería, etc.), el recurso a nanomedios (pódcast, uso de plataformas Web 2.0) y la gestación de espacios de discusión y formación enfocados en los impactos ambientales del extractivismo fortalecieron la interacción de la comunidad alrededor del abordaje de los problemas socioambientales y económicos provocados por el modelo de desarrollo dominante en los territorios. Asimismo, el repertorio de acciones comunicacionales contribuyó a activar la esfera pública local al concitar el debate social y suscitar la participación de múltiples sectores que por razones distintas asumieron esta cuestión como un asunto de importancia.

$\mathrm{Al}$ orientar las estrategias o acciones comunicacionales al ámbito local, los comités promotores lograron fortalecer la eficacia de la difusión de los mensajes y reconfigurar la praxis comunicativa desde la comprensión y resignificación de los esquemas hegemónicos que anidan en el sentido común. Al tiempo, recuperaron el buen sentido (mediante el uso de símbolos y discursos) inscrito en los valores inherentes a las prácticas colectivas relacionadas con el 
cuidado y la preservación de los bienes comunes que aún persisten en algunas comunidades. Las acciones colectivas desarrolladas por los comités promotores impactaron el campo de las mediaciones al recrear los símbolos asociados a la biodiversidad (con los cuales se ha procurado establecer una identidad local o nacional) para motivar la participación en la consulta, e incitaron a readecuar los formatos narrativos y medios de comunicación para este mismo propósito. En los comités promotores de las consultas populares, al igual que en la pléyade de movimientos sociales en América Latina, no hay una separación de base entre organización social y medios de comunicación (Zibechi, 2007). Las organizaciones sociales comunican en sí mismas, ellas mismas son medios y procesos de comunicación; de allí que una de las acciones por excelencia, más allá de la convocatoria a las consultas, fue la praxis comunicacional.

\section{Referencias bibliográficas}

Arbeláez, segundo municipio del Sumapaz en decir NO a proyectos extractivos. $(2017,11 \mathrm{de}$ julio). Colombia Informa. http://www.colombiainforma.info/arbelaez-segundo-municipio-del-sumapaz-en-decir-no-a-proyectos-extractivos/

Bocanegra, H. y Carvajal, J. E. (2019). Extractivisimo, derecho y conflicto social en Colombia. Revista Republicana, (26), 143-169.

Botia Flechas, C. J. y Preciado Beltrán, J. (2019). Resiliencia comunitaria: defensa del agua y del territorio en la cuenca del río Sumapaz, Colombia. Perspectiva Geográfica, 24(1), 13-34.

Cadavid, M. J. (2014). Disputas territoriales y conflictos socioambientales: lucha y solidaridad en torno al territorio y los recursos naturales. Revista Controversia, (202), 77-108. $\mathrm{http}: / /$ revistacontroversia.com/index.php?journal=controversia\&page $=$ article\&op=view\&path[]=9

Capriles, O. (2016). ¿Política de comunicación o comunicación alternativa? Revista Latinoamericana de Ciencias de La Comunicación, $12(23), 160-174$.

Carabaza González, J. (2006). Apuntes para comprender la cultura ambiental desde la comunicación. Global Media Journal México, 3(6).

Castañeda, A. (2017, 5 de julio). Arbeláez se prepara para la consulta popular. Fusagasugá Noticias. http://fusagasuganoticias.com/word/medio-ambiente/arbelaez-se-prepara-para-la-consulta-popular/

Castells, M. (1999). La era de la información. El poder de la identidad. Madrid: Siglo XXI.

Ceceña, A. E. (2017). Chevron: la territorialidad capitalista en el límite. En A. E. Ceceña y R. Ornelas (coords.), Chevron: paradigma de la catástrofe civilizatoria (p. 7-52). Madrid: Siglo XXI.

Cincoxtres. (2015, 26 de noviembre). Arbelaez dice NO a la petrolera y a la ANLA que la apoya [video]. YouTube. https://www.youtube.com/watch?v=8eZRpZ3bYQM

Colectivo Guacaná. (s.f.). Inicio [página de Facebook]. https://www.facebook.com/ groups/101184123556326/

Conde, M. (2017). Resistance to mining. A review. Ecological Economics, 132, 80-90.

Conde, M. y Le Billon, P. (2017). Why do some communities resist mining projects while others do not? The Extractive Industries and Society, 4(3), 681-697.

Consulta popular en Arbeláez para proteger municipio ante gran minería y petróleo. (2017, 
8 de julio). Soacha Ilustrada. http://soachailustrada.com/2017/o7/consulta-popular-arbelaez-proteger-municipio-ante-gran-mineria-petroleo/

Dietz, K. (2018). Consultas populares mineras en Colombia: condiciones de su realización y significados políticos. El caso de La Colosa. Colombia Internacional, (93), 93-117.

Downing, J. (2009). Integrando los niveles de la comunicación contra-hegemónica. https:// incom.uab.cat/catunesco/download/2010_Downing_guion_workshop_UAB.pdf

Downing, J. (2010). Nanomedios de comunicación: ¿medios de comunicación comunitarios? ¿O de red? ¿O de movimientos sociales? ¿Qué importancia tienen? ¿Y su denominación? [texto preparado con motivo de la conferencia "Medios comunitarios, movimientos sociales y redes”, organizada por la Cátedra Unesco de Comunicación InCom-UAB en colaboración con la Fundación Cidob (Centro de Estudios y Documentación Internacionales de Barcelona)]. Fundación Cidob.

El peligro de querer extraer petróleo en el Sumapaz (2017, 10 de julio). Semana Sostenible. https://sostenibilidad.semana.com/medio-ambiente/articulo/sumapaz-y-las-peligrosas-intenciones-de-sacar-petroleo-en-este-paramo/38176

Environmental Justice Atlas. (s.f.). https://ejatlas.org/country/colombia

Gutiérrez, V. y Silva, M. (2018). Propuesta pedagógica Escuela de promotores y promotoras en defensa del territorio de la provincia del Sumapaz. Polifonías, (1). http://revistapolifonias.pedagogica.edu.co/2018/12/o1/propuesta-pedagogica-mes/

Habermas, J. (1986). La esfera de lo público. Revista de Ciencias Sociales (Montevideo), (1), 7-10.

Helwege, A. (2015). Challenges with resolving mining conflicts in Latin America. The Extractive Industries and Society, 2(1), 73-84.

Hincapié, S. (2017). Entre el extractivismo y la defensa de la democracia. Mecanismos de democracia directa en conflictos socioambientales de América Latina. Recerca: Revista de Pensament I Anàlisi, (21), 37-62.

Instituto Latinoamericano para una Sociedad y un Derecho Alternativos (ILSA). (2014). El río Sumapaz, proyecto hidroeléctrico "El paso": agua y vida campesina en riesgo. https:// issuu.com/ilsaenred/docs/sumapaz

Left, E. (2014). La apuesta por la vida. Madrid: Siglo XXI

Martínez Alier, J. (2011). El ecologismo de los pobres. Madrid: Icaria.

Martínez Ortiz, A. y Aguilar Londoño, T. (2013). Estudio sobre los impactos socioeconómicos del sector minero en Colombia: encadenamientos sectoriales. Bogotá: Fedesarrollo.

McAdam, D., Tarrow, S. y Tilly, C. (2005). Dinámica de la contienda política. Barcelona: Hacer.

Misión de Observación Electoral (MOE). (2012). Mecanismos de participación ciudadana en Colombia: 20 años de ilusiones.

Monsalve, M. M. (2017, 7 de mayo). Consulta popular en Arbeláez para frenar petroleras. El Espectador. https://www.elespectador.com/noticias/medio-ambiente/consulta-popular-en-arbelaez-para-frenar-petroleras-articulo-692704

Moreno, J. (2018). Cuando el río suena agua lleva: defender para gobernar en la provincia de Sumapaz. Tesis de licenciatura, Universidad Santo Tomás.

Negrete, R. (2013). Derechos, minería y conflictos. Aspectos normativos. En L. Garay, M. Cebrera, J.; Espitia, J.; Fierro, R.; Negrete y L. Pardo (eds.), Minería en Colombia. Derechos, políticas públicas y gobernanza (p. 23-57). Contraloría General de la República.

Observatorio de Conflictos Ambientales (s.f.). http://168.176.238.67/

Ornelas, R. (2017). Trayectoria y competencia en el mercado mundial petrolero. En A. E. Ceceña y R. Ornelas (coords.), Chevron: paradigma de la catástrofe civilizatoria. Siglo XXI.

Oseguera, M. (2017). A la sombra de Sidney Tarrow. Conceptos básicos para el estudio de 
los movimientos de protesta. Política y Gobierno, 24(1), 189-212.

Pérez-Rincón, M. A. (2014). Conflictos ambientales en Colombia: actores generadores y mecanismos de resistencia comunitaria. Ecología Política, (48), 76-82.

Prieto, A. (2017). Conflictos socioambientales en los páramos de la sabana de Bogotá. Asociación Ambiente y Sociedad. https://www.ambienteysociedad.org.co/wp-content/ uploads/2017/o7/Publicacion_conflictos_socioambientales_paramos_Sabana_Bogota_Julio_2017.pdf

Radio Zumba La Turba. (2017, 13 de julio). Enredando las mañanas [audio en pódcast]. https://www.ivoox.com/entrevista-a-luis-jaime-ortiz-asojuntas-colombia-audios-mp3 rf_19787521_1.html

Ramírez, G. y Padrón, F. (2016). La consulta popular frente a proyectos de exploración y explotación minera. En J. C. Henao y A. C. González (eds.), Minería y desarrollo: minería y comunidades, impactos, conflictos y participación ciudadana (p. 415-465). Bogotá: Universidad Externado de Colombia.

Registraduría Nacional del Estado Civil. (2018, 21 de agosto). Comunicado de Prensa N. 0167. https://www.registraduria.gov.co/39-499-colombianos-acudieron-a-las.html

Rodríguez, C. (2010). De medios alternativos a medios ciudadanos: trayectoria teórica de un término. Folios, Revista de La Facultad de Comunicaciones, (21).

Svampa, M. (2009). Protesta, movimientos sociales y dimensiones de la acción colectiva en América Latina [ponencia presentada en las Jornadas de Homenaje a C. Tilly]. Universidad Complutense de Madrid / Fundación Carolina.

Svampa, M. y Slipak, A. M. (2015). China en América Latina: del consenso de los commodities al consenso de Beijing. Revista Ensambles, 2(3), 34-63.

Tilly, C. (2010, 14 de noviembre). Ampliar el "repertorio de acciones". Una entrevista con Charles Tilly. Viento Sur. https://vientosur.info/spip.php?article4879

Urkidi, L. (2011). The defence of community in the anti mining movement of Guatemala. Journal of Agrarian Change, 11(4), 556-580.

Urkidi, L. y Walter, M. (2011). Dimensions of environmental justice in anti-gold mining movements in Latin America. Geoforum, 42(6), 683-695.

Urkidi, L. y Walter, M. (2017). Community mining consultations in Latin America (20022012): The contested emergence of a hybrid institution for participation. Geoforum, 84, 265-279.

Walter, M. (2009). Conflictos ambientales, socioambientales, ecológico distributivos, de contenido ambiental. Reflexionando sobre enfoques y definiciones. Boletín Ecos, (6), 2-9.

Zibechi, R. (2007). Los movimientos sociales como sujetos de la comunicación. América Latina en Movimiento, (426), 16-23. 